\title{
Effects of Cold Band Application Treatment on Pain and Quality of Life in Migraineurs: A Self-Controlled Study
}

\author{
Sengul Uzen Cura ${ }^{1} \mathbb{D}$, Rengin Acaroglu ${ }^{2}$ \\ ${ }^{1}$ Department of Nursing, Faculty of Health Science, Canakkale Onsekiz Mart University, Canakkale, Turkey. \\ ${ }^{2}$ Istanbul University-Cerrahpasa, Department of Fundamentals of Nursing, Florence Nightingale Faculty of Nursing, Istanbul, Turkey. \\ Correspondence Author: Sengul Uzen Cura \\ E-mail: snglzn@gmail.com \\ Received: 23.07.2019 Accepted: 25.04.2020
}

\begin{abstract}
Objective: The aim of this study was to examine the effect of applying cold band treatment to migraineurs on the duration and severity of migraine headaches, and on migraine-specific life quality.

Methods: Patients referred to neurology clinic and diagnosed with migraine by a neurologist were examined prospectively. A self-controlled research design was applied to minimize individual differences. The sample group participating in the study were monitored over the course of four migraine attacks: two before and two during application period.

Results: Comparison of the mean values of pain duration for pre-application and application periods revealed no statistically significant difference $(p>0.05)$. However, there was found to be a significant difference between mean pain intensity total scores ( $<<0.05)$. At 30 th and 60 th - minute points, it was noted that the mean value of the total pain scores for the application period decreased significantly ( $<<0.05$ ). Also, it was recognized that the 24-hour Migraine Quality of Life Scale showed statistically significant increase in total score and in subscale scores when compared to pre-application period ( $p=0.0001)$.
\end{abstract}

Conclusion: The application of a cold band to forehead was found to have a positive effect in reducing pain severity and also improving quality of life.

Keywords: Cold application, migraineurs, nursing, pain, quality of life.

\section{INTRODUCTION}

The International Headache Society (IHS) defines migraine as a headache which reoccurs, which is so intense that it can seriously affect quality of life and which might last for hours; it emphasizes that migraine can alter individuals' physiological and emotional states, as well as their social and economic conditions (1). It is evident that the unpredictable nature of migraine can often cause individuals to experience fear and anxiety (2). Also, it can negatively affect their daily life activities, work / school performance and their general social functioning (3-5). Furthermore, it is commonly felt that the pain and incapacity experienced during a migraine attack is not limited only to the period of the attack itself, but also continues to affect the individual between attacks (6).

The main goal in the care and treatment of migraineurs is to enhance quality of life by reducing the frequency of attacks, and the severity and duration of the pain (6).
It is necessary to teach these individuals methods and practices for coping with pain by raising the level of their physical, social and psychological well-being, thereby improving their quality of life $(4,6)$.

A number of studies have advocated the use of herbal products, vitamins and minerals and also the benefits of methods such as applied pressure and hot and cold applications to prevent or relieve migraine $(3,7-9)$. In particular, cold application to the head is a method that has been used for many years in migraine treatment and is generally a responsibility of nursing staff (10-13) (Turkish Nurses Association, 2011). Some previous studies into the effects of cold application on headaches employed different application methods, such as: a complex helmet system that combines cold, heat and pressure (14); a cold gel cap attached at the neck and surrounding the whole head (15); and a cold neoprene band wrapped around the neck (13). 
However, to date, there do not appear to have been any studies carried out on this subject by nursing practitioners. The focus of this study was the use of a cold band applied to the forehead during migraine attacks. This method was chosen because the time of occurrence of migraine attacks is uncertain and this method is easy to use in any setting. Similarly, the forehead is the most commonly-reported locus for the experience of migraine and the band can be easily applied there.

In this context, the study was designed to evaluate the effect of local cold application to the forehead on headache intensity level and duration, and also on quality of life. It is anticipated that the results of this study might provide useful evidence for the improvement of patient care guidelines in future.

In this study, the following hypotheses were tested during any follow-up that was conducted.

Hypothesis $(H)$ 1: Local cold application on the forehead of the migraineurs shortens the length of pain.

Hypothesis $(H)$ 2: Local cold application on the forehead of the migraineurs decreases the severity of pain.

Hypothesis $(H)$ 3: Local cold application on the forehead of the migraineurs increases the quality of life.

\section{METHODS}

\subsection{Study Design and Sampling}

The study was completed within one year (August 2015 August 2016) using self-controlled pre-test and post-test research design at a single center. Ethical approval from Medipol University Clinical Research Ethics Committee was obtained (No: 108400987-379).

After the research sample was determined, an effect test was performed using the Visual Analogue Scale (VAS) scores from the study results previously obtained by SuprouseBlum and colleagues (2013). Based on these calculations, it was considered necessary to include 22 migraineurs in the sample with 0.80 power value, 0.05 level of significance, \pm 0.05 deviation. Finally, it was decided to proceed with the study with 30 patients who met the inclusion criteria, so that parametric tests could be applied, bearing in mind it was likely there would be some drop-out from the total number starting the study. These individuals were monitored throughout the duration of four attacks in total, two in the pre-application period and two in the application period, for pain severity, pain duration and quality of life.

Individuals who were diagnosed by a physician with migraine according to International Classification of Headache Disorders-II (CHD-II) criteria, and who met certain specified criteria, were included in the study. The participants had to be 18 years of age or above, who were not pregnant, who took only nonsteroidal anti-inflammatory (NSAID) analgesics, who had not used the cold application method before in order to relieve migraine, who had no record of cold allergies and whose attack frequencies were usually less than two months.

Patients with migraine who visited the neurology polyclinic and who met the research criteria, were informed on admission about the aims of the research, its scope, duration and what was expected from them. Written consent was obtained from the volunteers before including them in the sample. During the pre-application period, participants were not informed about the nature of the treatment in case they were tempted to try it before application. They were told only that it was known to be effective as a migraine treatment, it had no side effects, and it was a non-pharmacological intervention. They were assured that they would be able to quit at any time if they did not want to proceed. In fact, however, no participant withdrew from the study.

\subsection{Instruments}

The following items were employed in the data collection process: Patient Information Form, Patient Inspection Form, VAS and The 24-hour Migraine Quality of Life Questionnaire (24 h-MQoLQ). Patient Information Form consisted of three parts. The first included participants' personal details such as age, gender, marital status, occupation and educational status. Part 2 featured questions regarding the duration of the migraine attack, the location in which it took place, the frequency of attacks, aura presence, and any methods used to stop the pain.The third part contained questions about the effect of the cold application in relieving pain, whether or not there were any side effects (and, if so, the nature of these side effects), their intention to use the cold application again for migraine relief or not, and whether or not they were using other non-pharmacological applications. Patient Inspection Forms were prepared separately for the preapplication and application periods. They listed the contact details of the researcher and specified the type of data the patients were required to enter in the course of the attacks. Pre-application Inspection Form was designed to record the patients' own descriptive account of the starting-point and end-point of migraine attacks and their experience of pain levels. In the same way application period inspection form, collected the patients' descriptions of their experience at the start and end of the cold application period. VAS was used to translate the participants' subjective judgements into numerical values. The participants were required to indicate their perception of the pain level experienced on a $10 \mathrm{~cm}(100 \mathrm{~mm})$ ruler. This registered the complete absence of pain at one end and severe pain at the other. The $\mathbf{2 4} \mathrm{h}$ MQoLQ is a migraine-specific questionnaire which aims to quantify short-term changes in quality of life within the 24hour period after the onset of pain. There are fifteen items in total covering five pre-defined subscales of quality of life: Migraine Symptoms, Emotions-Anxiety, Work Functionality, Social Functioning and Energy/Vitality. It is possible to get a minimum of 1 point and a maximum of 7 points from each item in the seven-point Likert - type scale, and a minimum of 
3 and maximum of 21 points from each item on the quality of life subscale. The minimum possible score is 15 , and the maximum 105. The higher the score on the scale, the better the quality of the individual's life in relation to his or her migraine. The lower the score on the scale, the worse the quality of life. The Cronbach Alpha Value of the scale was found to be 0.84 . In this study a value of 0.79 was obtained for the pre-application period, and 0.89 for the application period $(16,17)$.

\subsection{Data Collection}

Individuals participating in the survey were observed during four migraine attacks: two before the cold application and two after. During the pre-application period, the first and second parts of the Patient Information Form were introduced to the participants, followed by the Pre-application Patient Observation Form, VAS and the 24h MQoLQ. The forms were explained in detail and any points requiring clarification were answered. During the application period, the information on the Patient Information Form was reviewed and any changes were recorded. The Application Period Patient Observation Form, VAS and the 24h MQoLQ were then issued. Instruction was provided on how to complete the forms. The cold application process was demonstrated and explanatory information provided about it and the material to be used. Feedback was received from the patients. The 'Cold Migraine Bands', with a form explaining the application method, were distributed to the participants so that they could apply them to their foreheads as directed as soon as the pain started.

The participants were asked to call the researcher after every attack in order the ensure all the relevant data was collected in full. Patients were called every two weeks by the researcher and questioned as to whether they had experienced a migraine attack. Those who said they had were invited to the polyclinic and their forms collected. They were issued with new forms to complete in the event of a further attack. The participants were invited to the polyclinic for interview after the application period had ended. Their forms were collected and the third part of the Patient Observation Form, containing the questions for evaluation after application, was issued to them.

\subsection{Statistical Analysis}

The data were analyzed using SPSS for Windows (Version 16.0). Descriptive statistics, such as mean, SD, number, and frequency, were used to characterize the research participants. The Wilcoxon Marked-Rank Test was employed to test the difference between groups in non-parametric data. Since the samples were collected independently from each other, the t test and ANOVA were used to determine whether the results were rational. The results were evaluated at $95 \%$ confidence interval, and at $p<0.05$ significance level.

\section{RESULTS}

The study was carried out with 30 patients. The average age of the patients included in the research was 35.47 \pm 8.95 .23$ of the patients were women, 16 had a university degree, 15 were government officers, and 16 were married.

When the sickness characteristics of the participants were analyzed: $43.3 \%$ were found to have been diagnosed with migraine for 11 years or more; the same figure of $43.3 \%$ was found for those who experienced pain in the pre-frontal area; $40 \%$ experienced a migraine attack once a month; $6.6 \%$ experienced a migraine attack every day; and $70 \%$ experienced aura symptoms before pain. The most common aura symptom was visual disorder, reported by $71.4 \%$; $80 \%$ of participants used medicine to relieve pain; $60 \%$ of them used non-pharmacological methods; and the most common non-pharmacological method was simply to rest in a dark and quiet environment, as stated by $33.3 \%$ (Table 1 ).

Table 1. Comparison of pain duration averages during pre-application and application periods $(n=30)$

\begin{tabular}{|l|c|c|c|c|}
\hline & Pre-application & $\begin{array}{c}\text { Application } \\
\text { Period }\end{array}$ & \multicolumn{2}{|c|}{} \\
\hline & Avg $\pm S D$ & Avg $\pm S D$ & $Z^{*}$ & P \\
\hline Total Pain Duration & $18.29 \pm 15.85$ & $20.21 \pm 13.27$ & -1.48 & 0.138 \\
\hline
\end{tabular}

*Wilcoxon Signed Rank Test

When the pain duration experienced in the pre-application and application periods was compared, no significant difference was detected ( $p>0.05$ ) (Table 2).

Table 2. Comparison of pain level averages in the pre-application and application periods $(n=30)$

\begin{tabular}{|l|c|c|c|c|c|}
\hline & $\begin{array}{c}\text { Pre- } \\
\text { application } \\
\text { Period }\end{array}$ & $\begin{array}{c}\text { Application } \\
\text { Period }\end{array}$ & & & \multicolumn{2}{c|}{$\begin{array}{c}\text { Percentage } \\
\text { Difference } \\
\text { Between Pre- } \\
\text { Application } \\
\text { and } \\
\text { Application } \\
\text { Periods }\end{array}$} \\
\hline $\begin{array}{l}\text { Total Pain } \\
\text { Duration }\end{array}$ & Avg $\pm S D$ & $A v g \pm S D$ & $t^{*}$ & $p$ & $\% 8$ \\
\hline Start & $5.2 \pm 1.6$ & $5.6 \pm 1.4$ & 1.634 & 0.113 & $\%$ \\
\hline 30.Minute & $6.4 \pm 1.4$ & $5.8 \pm 1.0$ & 2.169 & 0.038 & $-\% 9$ \\
\hline 60.Minute & $7.3 \pm 1.5$ & $5.7 \pm 1.0$ & 5.227 & 0.0001 & $-\% 22$ \\
\hline
\end{tabular}

*t-test *Anova

When the pain level averages in the pre-application and application periods were compared, no statistically significant difference was observed between them at the beginning ( $0 \mathrm{~min}),(p=0.113)$. The application period pain level at the 30th and 60th minutes points dropped by a significant level compared to the pre-application period $(p<0.05)$. This drop in pain level percentages was observed clearly between the two application periods. The pain level total points averages obtained were transformed from $0 \mathrm{~min}<30 \mathrm{~min}<60 \mathrm{~min}$ in 
the pre-application period into $0 \mathrm{~min}<30 \mathrm{~min}>60 \mathrm{~min}$ in the application period (Table 3).

Table 3. Comparison of point averages in the 24 h-MQoLQ during the pre-application and application periods $(n=30)$

\begin{tabular}{|l|c|c|c|c|} 
& $\begin{array}{c}\text { Average of pre- } \\
\text { application period }\end{array}$ & $\begin{array}{c}\text { Average of } \\
\text { application period }\end{array}$ & \multicolumn{3}{|c|}{} \\
\hline $\begin{array}{l}\text { Subscales of the 24- } \\
\text { hour QOLS }\end{array}$ & $\begin{array}{c}\text { Attack } 1 \text { and } \\
\text { Attack 2 }\end{array}$ & $\begin{array}{c}\text { Attack } 1 \text { and } \\
\text { Attack } 2\end{array}$ & \multicolumn{2}{|c|}{} \\
\hline Migraine Symptoms & $6.92 \pm 1.67$ & $8.70 \pm 2.22$ & -3.430 &, 001 \\
\hline Emotion/Anxiety & $6.95 \pm 5.53$ & $8.38 \pm 2.22$ & -3.114 &, 002 \\
\hline Work Functionality & $6.18 \pm 2.40$ & $8.62 \pm 2.30$ & -4.324 &, 0001 \\
\hline Social Functioning & $6.20 \pm 2.04$ & $8.83 \pm 2.50$ & -4.001 &, 0001 \\
\hline Energy-Vitality & $6.58 \pm 1.88$ & $8.22 \pm 2.35$ & -3.230 &, 001 \\
\hline Total & $32.83 \pm 6.84$ & $42.75 \pm 8.98$ & -4.314 &, 0001 \\
\hline
\end{tabular}

*Wilcoxon Signed Rank Test

It was noted that there was a statistically meaningful increase in the total points averages of the 24 h-MQoLQ in the application period compared to the pre-application period $(z=4.314, p=0.0001)$.

\section{DISCUSSION}

After the data on pain duration from the migraineurs were collated, the total points average of pain duration for the pre-application period was determined to be $18.29 \pm 15.85$ hours, and for the application period the corresponding figure was $20.21 \pm 13.27$ hours (Table 1 ). It is generally agreed that migraines are rarely shorter than 3 hours and usually last between 8 and 24 hours. However, they can last a few days and sometimes even up to a week $(6,9)$. In this study, our findings with regard to pain duration are consistent with the literature though there are only a limited number of studies on this aspect. However, the evaluation carried out after implementation of the cold application treatment revealed no significant difference between the total points averages over the pre-application and application periods $(p>0.05)$. Although there are a few studies in the literature examining the effect of cold applications on migraine pain, none have focused on their effect on the duration of pain application period $(11-13,15)$. With regard to this, H1 hypothesis was rejected.

In migraineurs the severity of the pain experienced varies from individual to individual. A high degree of severity might prevent them from carrying out their normal everyday activities (18). The data collected from participants during attacks showed that there was a statistically significant increase in the median severity of pain in the case of both attacks in the pre-application period ( $p<0.001$; Table 2$)$. For data collected during attacks within the application period, the median values of pain severity showed similar distributions $(p<0.05$, Table 2$)$. When the total pain level points averages in the pre-application and application periods were compared, no statistically significant difference was observed between the averages at the start point $(0 \mathrm{~min}),(p=0.113)$. However, at the 30th and 60 th minutes points a significant difference was detected $(p=0.038 ; p=0.0001)$ (Table 2). Thus, H2 hypothesis was confirmed. Similar results can be found in previous studies of the effect of cold application treatment on headaches $(13,15,18,19)$. In addition, the effect of cold application was investigated with regard to the experience of pain across a wide range of conditions, for example: following total hip surgery; after knee surgery; in cases of acute low back pain; postpartum episiotomy; for heel pain; in the post-operative period following an open abdominal operation; for pain due to chest tube removal; and for patients with primary osteoarthritis. The results of these studies indicate that cold application treatment has a positive effect (19-26).

For migraineurs, recurring episodes of headache, and persistent fear and anxiety about the uncertainty of when the next one will occur, can all have a disturbing effect on themselves and their family, as well as on their work and social life. A study by Powers et al (2003) found that children with migraine had similar quality of life scale scores to those with arthritis and cancer (27). Researchers in Canada revealed that half of migraineurs were unable to continue their daily activities during attacks and one third needed bed rest (28). Özkan and Ongun (2017), found that $53.1 \%$ of migraineurs were severely restricted in carrying out their normal daily activities, while the figure obtained by Gul and Mollaoğlu (2012) was 68.3\% (29, 30).

When the data on quality of life with migraine were analyzed, it was found that, for the first and second attacks in the pre-application period, the total average score for the 24 h-MQoLQ was $32.83 \pm 6.84$, rising to $42.75 \pm 8.98$ in the application period. Scale point averages were compared at the end of the pre-application and application period attacks. As a result, a significant increase in total quality of life scores in the application period was observed, compared to the pre-application period $(p<0.05$, Table 3$)$. With regard to this finding, $\mathrm{H} 3$ hypothesis was confirmed. Although to our knowledge no studies have been conducted into the direct effect of cold application on quality of life, it is recognized as a frequently used treatment method (31, 32 ). It is asserted that the higher the individual's score on the 24 h-MQoLQ, the higher their migraine-related quality of life will be $(16,17)$. The increase in migraine-related quality of life scale scores during the application period when compared to the pre-application period showed that the cold application had a positive effect in improving the quality of life of individuals suffering from migraine. However, given that the highest possible score on the 24 h-MQoLQ is 105 , it was noticeable that quality of life had not reached the expected level even at the end of the application period. This was taken as a reflection of the overall quality of life of the patients. 


\section{CONCLUSION}

In conclusion, the application of a cold band to the forehead of migraineurs was found to be an effective intervention in reducing the level of pain and improving migraine - related quality of life, but it had no effect on the duration of pain. It is recommended that a further study should be carried out with migraine patients, using different non-pharmacological methods to relieve the pain and then the results compared.

\section{Limitations of the Study}

The limitations of the study are as follows; the data's being dependent on self-report, the time between the migraine attacks being too long, the research's being limited to the sample group and not being able to perform any generalizations.

Source of Funding: This study was supported by Istanbul University Scientific Research Projects Unit. Project no: TDK2016-3781

\section{REFERENCES}

[1] Adams J, Barbery G, Lui CW, Pain F. Complementary and alternative medicine use for headache and migraine: a critical review of the literature. Headache 2013; 53(3): 459-473.

[2] Abu Bakar N, Tanprawate S, Lambru G, Torkamani M, Jahanshahi M, Matharu M. Quality of life in primary headache disorders: a review. Cephalalgia 2016; 36(1): 67-91.

[3] Evans RW, Taylor FR. "Natural" or alternative medications for migraine prevention. Headache 2006; 46(6): 1012-1018.

[4] Goolsby MJ. Migraine Headaches. J Am Acad Nurse Pract 2003; 15(12): 536-538.

[5] Mollaoğlu M. Trigger factors in migraine patients. J Health Psychol 2013; 18(7): 984-994.

[6] Wright WL. Assessing functional impairment during and between migraine attacks. Mayo Clin Proc 2008; 4(3): 201-207.

[7] Landy SH, Griffin B. Pressure, heat, and cold help relieve headache pain. Archives of Family Medicine 2000; 9(9): 792.

[8] Wells RE, Bertisch SM, Buettner C, Phillips RS, McCarthy EP. Complementary and alternative medicine use among adults with migraines/severe headaches. Headache 2011; 51(7): 1087-1097.

[9] Silberstein S, Holland S, Freitag F, Dodick DW, Argoff C, Ashman E. Evidence-based guideline update: pharmacologic treatment for episodic migraine prevention in adults: report of the Quality Standards Subcommittee of the American Academy of Neurology and the American Headache Society. Neurology 2012; 78(17): 1337-1345.

[10] Diamond S, Freitag FG. Cold as an adjunctive therapy for headache. Postgraduate Medicine 1986; 79(1): 305-309.

[11] Friedman M, Peterson S, Behar C, Zaidi Z. Intraoral chilling versus oral sumatriptan for acute migraine. Heart Disease 2001; 3(6): 357-361.

[12] Vanderpol J, Bishop B, Matharu M, Glencorse M. Therapeutic effect of intranasal evaporative cooling in patients with migraine: a pilot study. J Headache Pain 2015; 16(1): 5.
[13] Sprouse-Blum AS, Gabriel AK, Brown JP, Yee MH. Randomized controlled trial: targeted neck cooling in the treatment of the migraine patient. Hawaii J Med Public Health 2013; 72(7): 237241.

[14] Lance JW. The Controlled application of cold and heat by a new device (Migra-Lief Apparatus) in the treatment of headache. Headache 1988; 28(7): 458-461.

[15] Ucler S, Coskun O, Inan LE, Kanatli Y. Cold therapy in migraine patients: open-label, non-controlled, pilot study. eCAM 2006; 3(4): 489-493.

[16] Hartmaier SL, Santanello NC, Epstein RS, Silberstein SD. Development of a brief 24-hour migraine-specific quality of life questionnaire. Headache 1995; 35(6): 320-329.

[17] Iltuş F, Karadakovan A. The reliability and validity of Turkish form of "the 24-hour migraine quality of life questionnaire". Turkiye Klinikleri J Neur 2008; 3(2): 59-63.

[18] Freitag FG. The cycle of migraine: patients' quality of life during and between migraine attacks. Clinical Therapeutics 2007; 29(5): 939-949.

[19] Arankalle D, Wardle J, Nair PM. Alternate hot and cold application in the management of heel pain: a pilot study. The Foot 2016; 29: 25-28.

[20] Paiva CdSB, de Oliveira SMJV, Francisco AA, da Silva RL, Mendes EdPB, Steen M. Length of perineal pain relief after ice pack application: A quasi-experimental study. Women and Birth 2016;29(2): 117-122.

[21] Saito N, Horiuchi H, Kobayashi S, Nawata M, Takaoka K. Continuous local cooling for pain relief following total hip arthroplasty. J Arthroplasty 2004;19(3): 334-337.

[22] Kullenberg B, Ylipaa S, Soderlund K, Resch S. Postoperative cryotherapy after total knee arthroplasty - A prospective study of 86 patients. J Arthroplasty 2006; 21(8): 1175-1179.

[23] Watkins AA, Johnson TV, Shrewsberry AB, Nourparvar $P$, Madni T, Watkins CJ, Feingold PL, Kooby DA, Maithel SK, Staley CA, Master VA. Ice packs reduce postoperative midline incision pain and narcotic use: a randomized controlled trial. J Am Coll Surg 2014; 219(3): 511-517.

[24] Demir Y, Khorshıd L. The effect of cold application in combination with standard analgesic administration on pain and anxiety during chest tube removal: a single-blinded, randomized, double-controlled study. Pain Manag Nurs 2010; 11(3): 186-96.

[25] Yilmaz N, Kiyak E. The effects of local cold application on fibromyalgia pain. Int J Rheum Dis 2017;20(8): 929-934.

[26] İnan Ç, Kıyak E. The effect of hot and cold application on pain, stiffness and physical function in patients with knee osteoarthritis. HEMAR-G 2014; 16(2): 1-10

[27] Powers SW, Patton SR, Hommel KA, Hershey AD. Quality of life in childhood migraines: clinical impact and comparison to other chronic illnesses. Pediatrics 2003; 112(1): e1-e5.

[28] Leroux E. Impact of a nurse for migraine management: the IMPACT Project (IMPACT). 2013.

[29] Özkan I, Olgun N. The relationship between self efficacy, general self disease management strategies in coping with pain and quality of life in migraine patients: Testing a theoretical method Journal of Human Sciences 2017; 14(4): 3389-3404.

[30] Gül S, Mollaoğlu M, editors. Characteristics of migraine pain and effects on the daily activity of pain in individuals with migraine. Yeni Symposium; 2011. 
[31] Kazan E. Cold applications and nursing care. Hacettepe University Faculty of Health Sciences Nursing Journal 2011; 18(1): 73-82.
[32] Bag B, Karabulut N. Pain-relieving factors in migraine and tension-type headache. J Clin Pract 2005; 59(7): 760-763. 